\title{
Reconciling the Tradeoff between Economic and Ecological Objectives in Habitat-Tree Selection: A Comparison between Students, Foresters, and Forestry Trainers
}

\author{
Hannes Cosyns, Daniel Kraus, Frank Krumm, Tobias Schulz, and Patrick Pyttel
}

Habitat trees provide microhabitats for many forest-related species, and thus habitat-tree retention is one of the main measures to integrate nature conservation objectives into forests managed for wood production. By setting aside habitat trees, forest managers have to solve a crucial tradeoff between economic and environmental benefits. Therefore, it is of major importance that trees with desired characteristics are retained as habitat trees. In this study, we analyze habitat-tree selection. Specifically, we are analyzing the outcome of a habitat-tree selection exercise that took place in a so-called "marteloscope" or "tree marking training site" with silviculture trainers, district foresters, and forestry students. Our results show that participants consistently selected habitat trees with a low economic value. However, the habitat values of the selected trees were highly variable. Selection behavior depended on participants' expertise, with forestry trainers making more consistent decisions and outperforming the students as well as the foresters. Our results show that the selection of optimal habitat trees is not self-evident. We provide some ideas about how it can be improved, benefiting both ecological and economic forest management objectives.

Keywords: marteloscope, tree marking, tree selection, multifunctional forestry, microhabitats

$\mathrm{H}$ abitat trees are standing trees with a specific significance for fauna and flora, bearing so-called tree related microhabitats such as: cavities, injuries and wounds, crown dead wood, epiphytes, and nests (Kraus et al. 2016, Larrieu et al. 2018). The frequency and quality of these microhabitats are crucial for a substantial share of forest-related species, which strictly or primarily depend on them for their survival (Bütler et al. 2013, Larrieu et al. 2014). Habitat trees are therefore key drivers for biodiversity in forest ecosystems and important components of a forest's functional network of old-growth elements (Vandekerkhove et al. 2013). A substantial number of studies have sufficiently demonstrated the importance of tree microhabitats for highly specialized (e.g., Palmer 1986, Ranius and Hedin 2001, Lehikoinen et al. 2011, Horak et al. 2012) as well as more generalist species (e.g., Winter and Moller 2008, Regnery et al. 2013, Quinto et al. 2014). In natural forests, habitat trees are abundantly present (e.g., Meyer and Schmidt 2008). In managed forest, however, they are often very rare or even absent, because thinning systematically eliminates "defective" trees with low economic value, which is commonly the case for trees hosting microhabitats or those with a high potential for their development (Bütler et al. 2013, Vandekerkhove et al. 2013). The term "habitat trees" can be broadly interpreted, and names such as veteran trees, monumental trees, historical trees, or cavity trees often refer to habitat trees, which have additional characteristics besides the presence of habitat structures. In this study, we focus on living habitat trees as the bearers of microhabitats because this is how they are typically observed and valued in a regularly managed forest.

Today, the concept of biodiversity enhancement by increasing microhabitat densities through retention of single trees, tree groups, or larger old growth forest patches is finding its way into forest management in many regions all over the world (Gustafsson et al. 2012). In forests managed for timber production, selecting habitat trees is one of the main measures to integrate nature conservation goals with economy-related objectives. In a European

Manuscript received August 27, 2017; accepted July 20, 2018; published online October 3, 2018.

Affiliations: Hannes Cosyns (hannes.cosyns@wsl.ch), Frank Krumm (frank.krumm@wsl.ch), Tobias Schulz (tobias.schulz@wsl.ch), Swiss Federal Research Institute for Forest, Snow and Landscape Research, 8903 Birmensdorf, Switzerland. Daniel Kraus (d.kraus@integrate-foundation.org), EFI Central European Regional Office EFICENT, 79100 Freiburg, Germany. Patrick Pyttel (patrick.pyttel@waldbau.uni-freiburg.de), Chair of Silviculture, University of Freiburg, 79085 Freiburg im Breisgau, Germany. 
context, practical guidelines recommend a retention of 2-10 habitat trees per hectare (Niedermann-Meier et al. 2010, Mergner and Kraus 2013, Larrieu et al. 2014, Simonsson et al. 2015). Whether or not this is sufficient is of course dependent on the objectives, the species involved, and the prevailing site conditions. However, research shows that current standards used by many forest managers are insufficient to preserve microhabitat diversity at stand level (Bütler and Lachat 2009, Larrieu et al. 2014).

Retention of habitat trees is of key importance from an ecological perspective but can imply financial loss. Although habitat trees with a high ecological value are generally suspected to have a low economic value, this is not always the case, and considerable timber value can be lost by excluding a (habitat) tree from harvest (Niedermann-Meier et al. 2010). In addition, habitat trees occupy growing space over several rotations. A well-considered selection of habitat trees with a focus on a high ecological and low economic value is therefore considered of main importance with regard to the ecology-economy tradeoff (Niedermann-Meier et al. 2010).

Tree selection, including habitat-tree retention, is a crucial silvicultural activity, because it will determine what a forest will look like in the future and which functions it will be able fulfill. It is, in addition, a time-consuming process that incurs significant costs (Sydor et al. 2004). Nonetheless, tree selection as individual or social decisionmaking has scarcely received any attention in scientific literature. Only recently, several studies on the topic were published with a focus on the impact of expertise on tree-selection decisions (Pommerening et al. 2015, Spinelli et al. 2016, Vítková et al. 2016, Pommerening et al. 2018). These studies assessed the results of thinning practices and the selection of future crop trees. Recurrent for all studies was the high interpersonal variability when it comes to tree selection. The effect of expertise was rather inconclusive, though: Spinelli et al. (2016) did not find any effect of expertise, whereas Vítková et al. (2016) observed a clear influence of a participant's background. In contrast to the few studies on thinning practices, no studies have been published, to the authors' knowledge, on habitat-tree selection.

Tree microhabitat inventories, and in a broader context the selection of habitat trees, is sometimes put forward as a cost-effective method for which no expert knowledge is needed and something that more or less anyone can perform (Regnery et al. 2013). However, microhabitat detection and habitat-tree selection are probably not as straightforward as assumed. Paillet et al. (2015) found that microhabitat detection and categorization differ considerably between persons (so-called observers). This observer effect was high for both novice and experienced participant groups, with no significant differences between both groups. In addition, detection probabilities for many microhabitats were low, including dead crown wood (15\%), bark pockets (10\%), cracks (10\%), and even woodpecker cavities (40\%). False-positive detections (observations of a particular microhabitat type when there is actually another type or no microhabitat at all) and a very high interpersonal variability of these figures add to the low reliability of microhabitat detection. Paillet et al. (2015) thus came to the conclusion that microhabitat inventory is not as easy as sometimes claimed, and observer effects should be better taken into account.

Our study puts an emphasis on the tradeoff between economic and ecological objectives that is always inherent in habitat-tree selection in the productive forest, and we thus want to deepen our knowledge about which trees (with which economic and habitat characteristics) are selected as habitat trees and what the influence of a person's expertise, in terms of a different professional background, is on this decision. First, we expect that generally, the selection of habitat trees shows a large interpersonal variability, although we also expect this variability to be contingent on the expertise, i.e., the professional background of the participants. Second, we also expect that selected habitat trees will generally have a relatively low economic and a relatively high ecological value. Third, we further expect the economic and habitat value of the selected trees to be highly contingent on the different professional groups examined. Fourth, if we compare the trees selected by the different groups with a randomly chosen hypothetical solution that should solve the tradeoff between economic and ecological objectives best, we expect significant differences between groups of participants.

\section{Methods and Materials Site Location}

Exercises on silvicultural decisions-making and tree selection ideally take place in so-called "marteloscopes" or "tree-marking training sites." These marteloscopes, in which each tree has been inventoried (measuring different features such as spatial position, diameter at breast height, etc.), have primarily been developed for didactical reasons and are used as training sites for forest students and foresters (Mordini and Rotach 2010, Kraus et al. 2018). Results of marteloscope exercises sporadically appear in praxis literature (e.g., Mordini and Rotach 2010, Van Daele et al. 2011, Petit et al. 2014, Allenspach et al. 2015), but it is not until recently that researchers have rediscovered these plots for investigating tree-selection behavior and decisionmaking in the forest more systematically (Pommerening et al. 2015).

\section{Management and Policy Implications}

Our study shows that the selection of habitat trees with desired characteristics is not straightforward and that a specific expertise is needed in order to do so. For practice, this implies that if habitat trees are to be selected in a stand, for example in the scope of an integrated forest-management approach, this should be done by experts. It requires expertise which is not necessarily readily present by foresters and should be gained through specific training programs focusing on distinguishing the different microhabitat structures, their characteristics, and their value for different species and species groups. Practical training sessions on microhabitat identification and classification will ultimately have to be adapted to real-world working conditions. In addition, we suggest the development of clear practical guidelines that enable practitioners to easily assess a tree's habitat value within a limited time frame. For policy, our results indicate that the upcoming idea to include nonexperts such as citizens in habitat-tree inventorization should be considered carefully. Although very obvious habitat trees with clear features are probably easily detected by nonspecialists in more complex environments, as was the case in our study plot, specific expertise is needed to select habitat trees of high ecological quality. Proper theoretical knowledge and practical training should be provided to the participating parties. The marteloscopes seem to be a very promising tool with which to transfer this knowledge and, if promoted accordingly, could play an important role in the educational process of foresters and other stakeholders. 
The present study took place in the so-called Rosskopf Marteloscope (Freiburg, Germany) (Figure 1). The Rosskopf Marteloscope is located at an altitude of $400 \mathrm{~m}$ asl, with a precipitation of $943 \mathrm{~mm} /$ year, and comprises a multilayered, 105-year-old stand, presently dominated by Pseudotsuga menziesii (Douglas-fir), Abies alba (silver fir), and Fagus sylvatica (European beech), and a minor presence of Pinus sylvestris (Scots pine), Picea abies (Norway spruce) and Quercus petraea (sessile oak). The plot contains 313 stems with a total volume of $629 \mathrm{~m}^{3}$. This marteloscope is part of the European network of marteloscopes that was established in a project called Integrate+ (Kraus and Schuck 2016). The marteloscope has been established according to methods and procedures explained in Schuck et al. (2015): All plots are rectangular and 1 ha in area. Trees larger than $7 \mathrm{~cm}$ in diameter at breast height (dbh) were numbered, mapped, and measured (dbh, height, species).
Additionally, the timber quality of each measured tree was assessed by the local foresters, and the ecological features (number and type of microhabitats) were assessed based on the tree microhabitat catalog, which was developed by various experts on tree microhabitats and corresponding species (Kraus et al. 2016). The inventory team (ideally two teams with two assessors in each team) used binoculars to assess all visible microhabitats on each tree, from the ground. A tree microhabitat is a distinct, well-delineated structure that occurs on living or standing dead trees. It constitutes a particular and essential substrate or life site for species or species communities during at least a part of their life cycle to develop, feed, shelter, or breed (Larrieu et al. 2018). All visible structures such as dead branches, cavities (excavated or decayed), growth deformations, epiphytic structures, and nests were assessed, described, and counted according to size and developmental categories (Kraus et al. 2016).

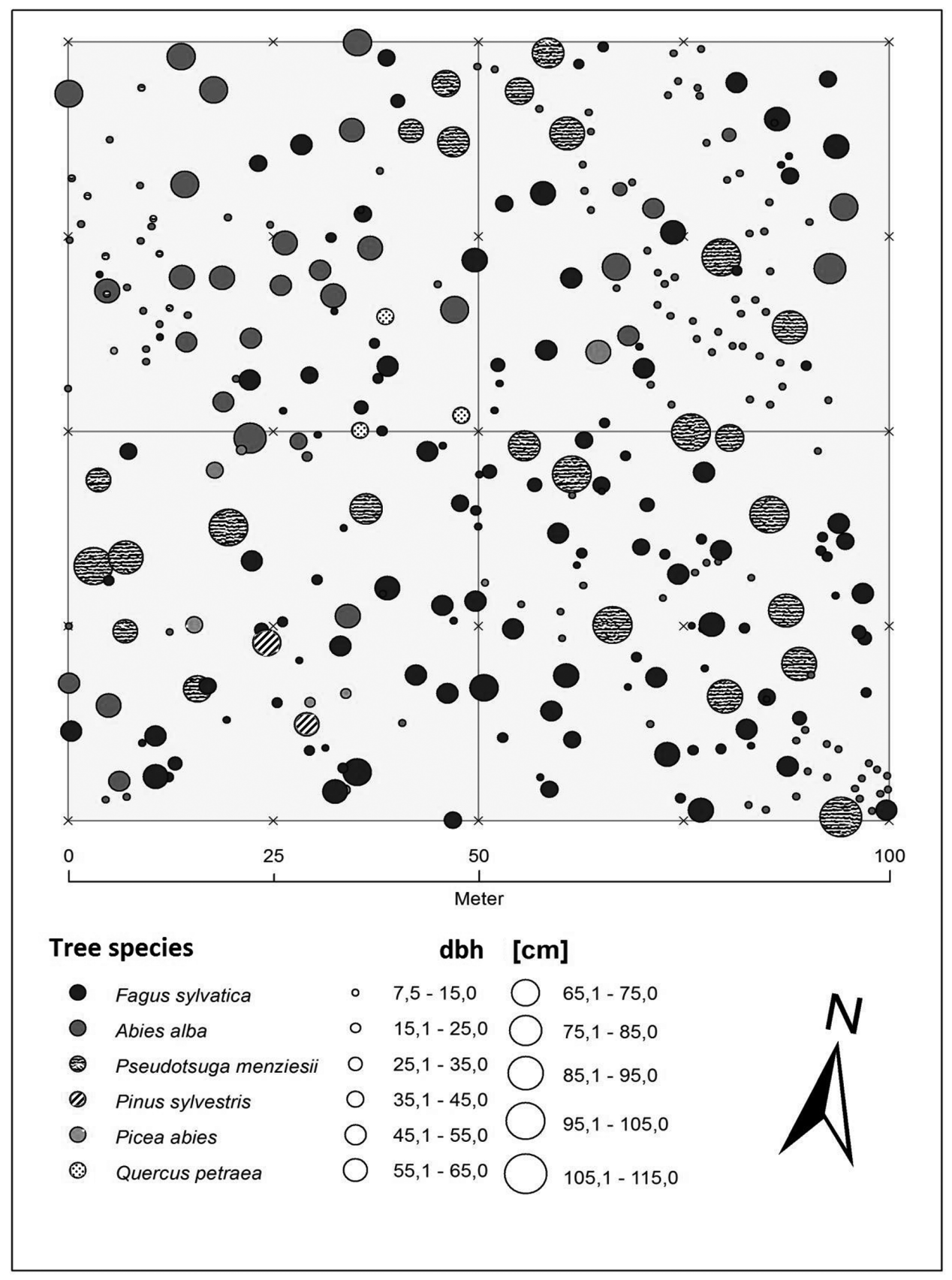

Figure 1. Rosskopf Marteloscope, a 1-ha plot dominated by Douglas-fir, silver fir and European beech (Kraus et al. 2015). 
The economic and habitat values of each tree have been calculated in accordance with Kraus et al. (2018). A tree's economic value was calculated based on the available volumes of timber of different quality classes multiplied by the local wood prices. The habitat value of a tree was calculated as a composite index based on a combination of (1) the number and type of microhabitats (including quality measures such as size of cavities, sun-exposure of dead branches, etc.), (2) their rarity, and (3) the time a specific microhabitat needs to develop (e.g., mold cavities provide habitats for highly specified organisms and need a long time to develop). The assessed counts were calculated into the mentioned index with an algorithm considering the above-mentioned weighing factors (1-3). More detailed protocols and formulas on marteloscopes of the Integrate+ project and attributing tree values within these marteloscopes are given by Kraus et al. (2018) and Schuck et al. (2015).

Both the economic and habitat values only take into account the present value of the trees. This implies that the future economic value of the trees is discarded, and so is the future habitat value. The latter is of importance because trees with specific characteristics (e.g., forks, large dbh) have a higher chance of developing microhabitats than other trees (Vuidot et al. 2011). Of course, the habitat value of all trees is changing over time (e.g., Zielinski and Schlexer 2015).

\section{Marteloscope Exercise}

The exercise analyzed in this paper encompassed different (educational) objectives. Here we describe the general outline of the exercise focusing on the part that is important for the objectives of this study: habitat-tree selection.

This exercise took place at the Rosskopf Marteloscope in April 2015. Three groups participated, each consisting of six persons and characterized by very different types and degrees of expertise in silviculture: first, so-called "trainers for silviculture" employed by the forest administration Baden-Württemberg, who are experienced trainers for silvicultural federal standards (referred to hereafter as forestry trainers); second, district foresters from the forest administration of the city of Freiburg, experienced in all fields of practical forest management (referred to hereafter as foresters); and third, second-semester MSc Forestry students at the Albert-LudwigsUniversity Freiburg, who have only limited experience in applied silviculture (referred to hereafter as students).

District foresters are responsible for all kinds of practical/operational forest management in their district, and the selection of trees for tending and harvesting operations is part of their everyday duties. However, their selection decisions have to follow certain management rules. These rules are decided by the leaders of the federal forest authorities (i.e., the ministry), and it is the forest trainers' duty to teach these rules to the local foresters. Although the foresters work locally, the trainers travel the country and give lectures and trainings. All local foresters were educated as foresters to fulfill and supervise technical processes and tasks (at universities of applied science). Most forest trainers were educated in forestry science at full universities and were further educated for their role as trainers.

At the beginning of the experiment, the participants were given a short introduction about the marteloscope. Next, they were given management instructions for the stand, based on the local forestmanagement plan. In our exercise, all participants were asked to aim at the following commercial and ecological objectives:
Please select $185 \mathrm{~m}^{2} /$ ha high-quality logs for harvesting. Choose a further five living trees with the highest possible ecological value ("habitat trees"). While choosing trees, only the ecological and economical value of the single tree shall be considered. There is no restriction with respect to the spatial distribution of either the retention trees or those selected for timber production. (translated from German)

Over approximately $1 \mathrm{~h}$, participants went individually through the marteloscope and wrote down the identification numbers of habitat trees and the trees they would harvest. Finally, the results of the participants' decisions were collected and discussed on-site using a specifically designed simulation matrix based on Microsoft Excel. More information on the exercise protocol can be found in Kiehne (2015).

\section{Data Analysis}

To assess participants' agreement regarding habitat-tree selection, we employ the agreement index $B$ proposed by Vítková et al. (2016), which is based on an agreement index originally developed by Zucchini and Von Gadow (1995).

$$
B=\frac{\sum_{k=1}^{K}\left|2 x_{k}-n\right|}{K \cdot \sum_{x=0}^{n}|2 x-n| \cdot\left(\begin{array}{r}
n \\
x
\end{array}\right) \cdot \hat{p}^{x} \cdot(1-\hat{p})^{n-x}}
$$

where $n$ denotes the number of test persons, $K$ represents the number of trees in the plot, and $x$ denotes the number of persons that mark a particular tree. $n-x$ is the number of persons who do not mark a particular tree. $X_{k}$ denotes the number of persons who marked tree $k$, with $\hat{p}$ denoting the mean number of marked trees calculated for all participating persons. In this index, the sum of absolute differences of all trees and persons is divided by the expected sum of the absolute differences. The expectation is based on the binominal probability function.

Independent decisions (or a lack of agreement) are indicated by values of $B-1$. A tendency toward agreement is indicated by values of $B$ higher than 1. Disagreement, on the other hand, prevails if $B<1$, with perfect disagreement being represented by $B=0$.

To analyze whether or not participants with different expertise selected habitat trees from different species, a frequency analysis was applied within a contingency table and tested with a chi-square test. If a statistically significant deviance from independence was found for the contingency table, a post hoc analysis of the adjusted residuals was carried out, according to Beasley and Schumacker (1995), to identify between which cells of the contingency these differences could be located.

For further analysis, a master-solution was added for comparison reasons. To calculate the master-solution, we simulated six participants each selecting a set of five trees with a high aggregated ecological and low aggregated economic value, because such solutions reconcile the tradeoffs between ecological and economic objectives in a favorable way (Niedermann-Meier et al. 2010). For this purpose, we created a pool of all possible solutions of selecting five trees with a high aggregated habitat value (higher than 300) and low aggregated economic value (lower than $€ 1000$ ), which adds up to 84 "best" combinations of selecting five trees in the entire stand. From this pool, we took six solutions at random, thus simulating the choice of six participants. 
Subsequently, ecological and economic parameters of the master-solution and participant groups were compared. Each group consisted of six persons performing the marteloscope exercise and thereby selecting each five habitat trees, which resulted in a total of 30 observations per group and a total $n$ of 120 . Preconditions for parametric data analysis were met, and groups' means were compared using a $t$-test or ANOVA (dbh, volume, mean number of microhabitats per tree, mean number of microhabitat types per tree, mean habitat value per tree, mean economic value per tree).

To study the tradeoffs participants made between ecological and economic objectives, we compared the aggregated habitat and economic value of the five retained trees between the participants. For such tradeoff situations, the set of possible choices (aggregated habitat and economic values of any five retained trees) can be thought of as points within a two-dimensional space, with the aggregated economic and the habitat values as its dimensions. Given a certain choice, another choice could result in a "pareto-improvement" (Ehrgott 2005) if it resulted in an improved value on one dimension without degrading the other objective. Because habitat trees are preferred if they have a high ecological but a low economic value, choices that lie toward the bottom right frontier of the set of potentially possible choices are preferred. At this frontier, those potential choices can be connected that have no (locally) more preferred option between them; they form the so-called pareto-front. This pareto-front we have plotted together with the entire set of possible choices as well as the actual choices of each participant for visual interpretation purposes (compare Figure 4).

To gain an insight into differences not only at the level of the retained trees but also at the level of retained microhabitats (through habitat-tree selection) between different expert groups, a nonmetric multidimensional scaling (NMDS) ordination, applying BrayCurtis dissimilarity (Kruskal and Wish 1987) was used. Proceeding from a matrix that contains the number of inventoried microhabitats per microhabitat type (columns) that were retained by the different participants (row), this analysis collapses all information into two basic dimensions and allows mapping of the microhabitats themselves as well as the decisionmaking groups within this two-dimensional space. In this plot, the (closer) distance between points is an indication of (higher) similarity.

Next, an analysis of similarities (ANOSIM), based on the BrayCurtis dissimilarity matrix, was applied to test statistically whether there were any significant differences between the microhabitats the different expert groups retained. In addition, a similar percentage analysis (SIMPER) was performed using Bray-Curtis dissimilarities (Clarke and Warwick 2001) to complement the results of the ANOSIM and to show which variables explained the observed dissimilarities between the expert groups. SIMPER provided data on the cumulative distribution of those microhabitats that are most influential for the dissimilarity between different groups of experts. For more detailed interpretation of the results provided by SIMPER, the latter were compared with the raw data of retained microhabitats (at the subject level).

The software-packages $\mathrm{R}$ version 3.4.3 (R Core Team 2017) and SPSS Inc. Version 23.0 (IBM Corp 2015) were used for data handling and analysis.

\section{Results}

The index of agreement $B$ (Vítková et al. 2016) unveiled a relatively low agreement between the different participants in each group when it comes to habitat-tree selection. In our case, the potential maximum value of $B$ (which corresponds to all participants selecting the same set of five habitat trees) equals 1.068, whereas the minimum value (corresponding to all participants selecting different trees) equals 0.9999. The highest index value, indicating higher agreement, was found for the forestry trainer group (1.0195), followed by the district foresters (1.0065) and the students (1.0043). All these index values are closer to 1 , which indicates a rather high independence of decisions, however. The agreement within and between different groups appears to be low also because the majority of the habitat trees were selected by only one person (Figure 2).

Tree-species frequencies were analyzed in a contingency table (Table 1) to see which expertise group selected which species as
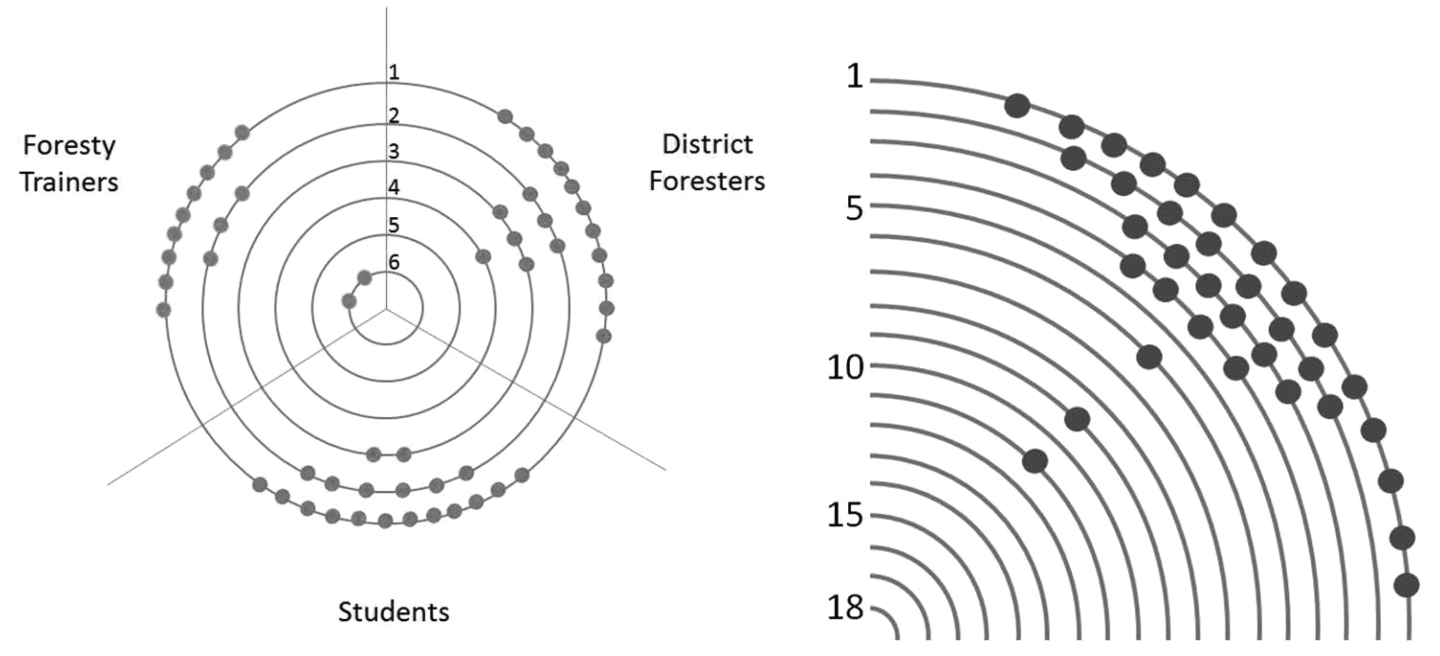

Figure 2. Each dot indicates a tree, and the larger circle on which they are positioned indicates how many participants selected the tree as a habitat tree. Thus, a dot close to the center represents a tree selected by several participants, whereas a dot on the outer circle represents a tree which was selected by only one participant. On the left, the number of results per group is shown (six participants per group), on the right of all participants together (18 in total). Both figures indicate overall a very low agreement between participants, with a few trees reaching a higher level of agreement. 
habitat tree. A chi-square test indicated significant differences between the groups $\left(\chi^{2}=15.618 ; \mathrm{df}=8 ; P=0.048\right)$. Post hoc analysis of the adjusted residuals showed that forestry trainers selected significantly more beeches (93\%) as habitat trees than the district foresters (57\%). In total, participants retained $73.3 \%$ beeches, $11.1 \%$ silver fir, $11.1 \%$ sessile oak, 3.3\% Scots pine, and 1.1\% Douglas-fir as habitat trees.

In the next step, mean values of ecological and economic parameters were compared between the different participant groups as well as with the master-solution; the latter representing a favorable tradeoff solution between ecological and economic objectives (see Data Analysis section). A one-way ANOVA indicated no significant difference between the groups for characteristics such as dbh $(P=0.232)$ or tree volume $(P=0.127)$. Significant differences

Table 1. Cross-table: (2) tree species of the selected habitat trees per participating group.

\begin{tabular}{|c|c|c|c|c|c|c|}
\hline \multicolumn{7}{|l|}{ Group $\times$ tree species } \\
\hline \multicolumn{7}{|l|}{ Count } \\
\hline & \multicolumn{5}{|c|}{ Tree species } & \multirow[t]{2}{*}{ Total } \\
\hline & Fagus & Pseudotsuga & Pinus & Abies & Quercus & \\
\hline \multicolumn{7}{|l|}{ Group } \\
\hline Foresters & 17 & 0 & 1 & 6 & 6 & 30 \\
\hline Students & 21 & 1 & 2 & 2 & 4 & 30 \\
\hline Forestry trainers & 28 & 0 & 0 & 2 & 0 & 30 \\
\hline Total & 66 & 1 & 3 & 10 & 10 & 90 \\
\hline $\begin{array}{l}\text { Frequency in the } \\
\text { whole } 1 \text {-ha plot }\end{array}$ & 135 & 33 & 2 & 136 & 3 & \\
\hline
\end{tabular}
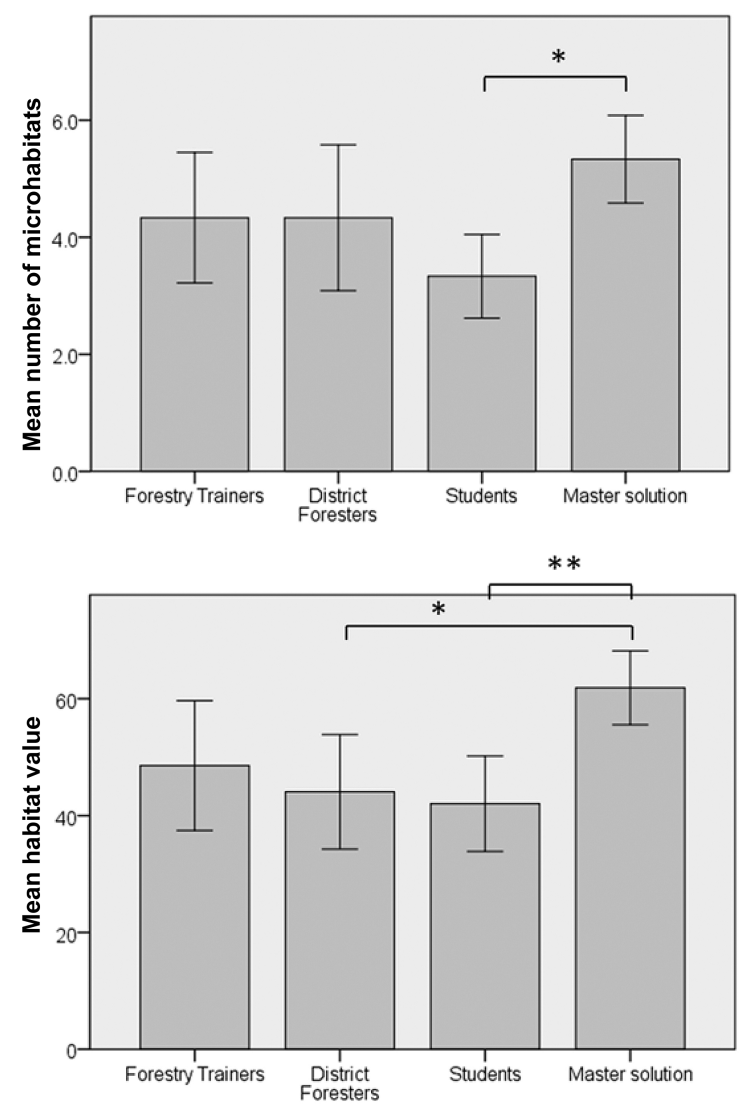

between the groups can be found, however, for the number of microhabitats $(P=0.039)$ and the habitat value $(P=0.009)$ (Figure 3 ). Although students visually seemed to have selected habitat trees with lower habitat and higher economic scores, the post hoc Tukey analysis did not indicate any significant differences between the different participant groups, only significant differences between the groups and the master-solution.

To show how well participants selected their five habitat trees, Figure 4 displays for each participant the aggregated economic and habitat value for their actual choices. In addition, these aggregated values have been calculated for all possible combinations of selecting five living trees within the plot (the cloud of gray triangles in the background of Figure 4). The results show that participants consistently selected habitat trees with a low economic value, thus leading to a low aggregated economic value $(20 \%$ of total range on the $y$-axis). The aggregated habitat value, on the contrary, shows a large variability between the participants, with the highest value being a threefold of the lowest one (67\% of total range on the $x$-axis). The plot shows again that forestry trainers were more consistent than the other participant groups; the variability of the economic and habitat value between forestry trainers was lower. Note also that for the forestry trainers, the variability on the habitat scale was greater than the variability on the economic scale.

In addition, the pareto-front (see Data Analysis section) was plotted on Figure 4, representing the points that reconcile the tradeoff between habitat and economic values in a most optimal way (the potential choices, i.e., combinations of five trees, at the outer bottom right bound of all possibly combinations of five trees,
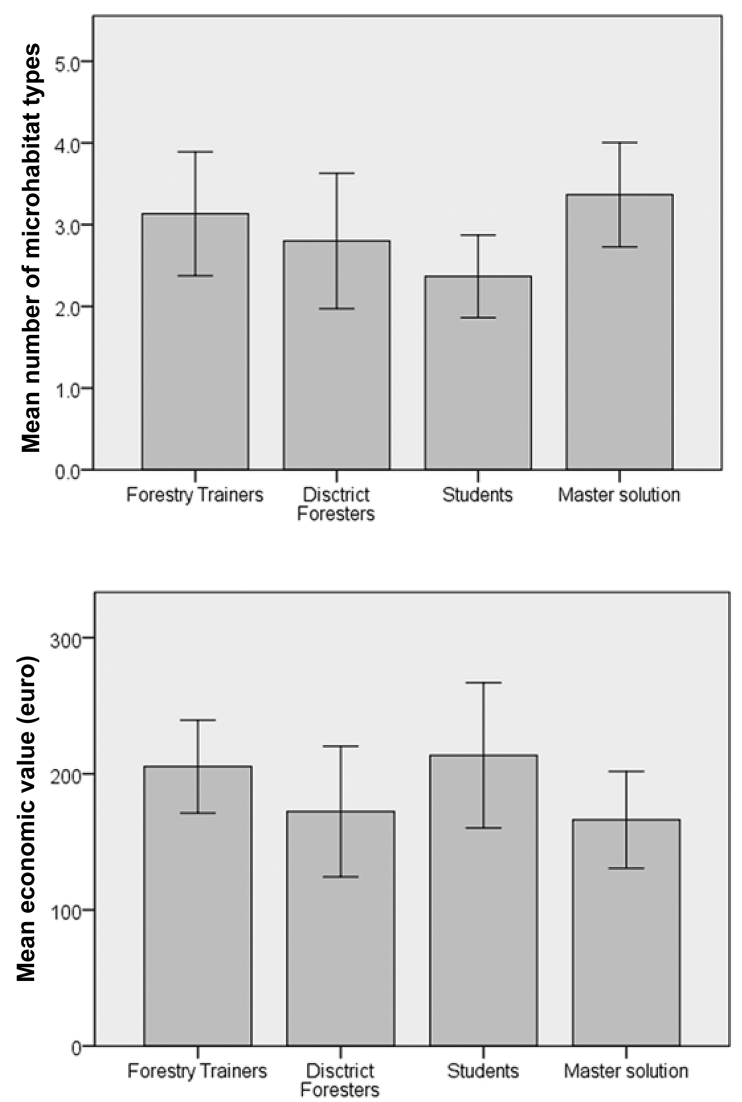

Figure 3. Mean values of several tree characteristics of the retained habitat trees as selected by different participating groups (error bars represent $95 \% \mathrm{Cl}^{*}{ }^{* P}<0.05 ;{ }^{* *} P<0.01$ ). 
connected with a dashed line in Figure 4). Going from left to right on the pareto-front implies that any "gained" (increasing) habitat value would have to be compensated by "lost" (increasing) economic value of the chosen habitat-tree combination. The results of the forestry trainers lay on average closer to the pareto-front, thus indicating that they made a better tradeoff between ecological/habitat and economic objectives than the other two groups.

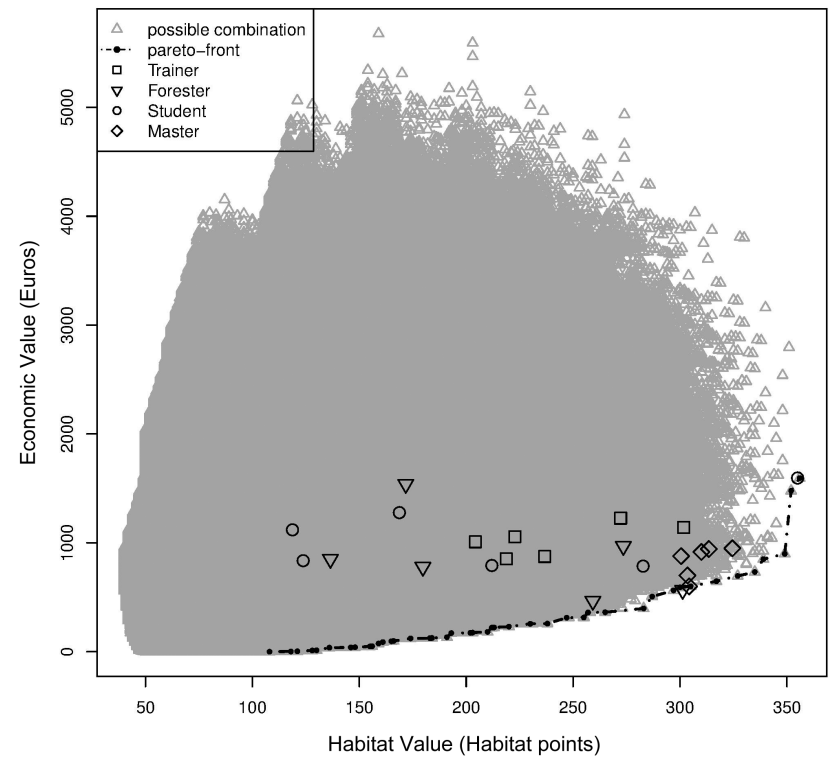

Figure 4. Cloud of gray triangles in the background representing all possible combinations of selecting five living trees within the marteloscope, plotted according to their aggregated economic and habitat values. This means that all possible ways of selecting five (habitat) trees are represented by this cloud. The other symbols represent each participant's actual selection of five habitat trees, and the sum of these trees' respective economic and habitat value. Symbols and colors vary according to the group to which they belong. The pareto-front is indicated as a black, dotted line and represents the best solutions to solve the ecology-economy tradeoff, retaining a (high) habitat value at minimum economic costs.
Note that two district foresters have solutions which are very close to the pareto-front. This however, is because these two participants included a dead tree (with an economic value of 0 euros) in their selection, although instructions were given not to do so. Hence, their respective scores would have been further away from the pareto-front if they had included a living tree instead of a dead tree.

In the whole 1-ha plot, a total of 237 microhabitats were present on the trees belonging to 29 different microhabitat types. By selecting five habitat trees, a forestry trainer included on average 19 microhabitats belonging to 9.7 different microhabitat types, a forester 20 microhabitats and 10.3 types, a student 14 and 7.0, respectively, and a master solution 23 and 9.2.

We found [NMDS, with a stress level $=0.16<0.2$, indicating a good representation of our data through the reduced dimensions (Kruskal and Wish 1987), Figure 5] that forestry trainers selected a combination of five habitat trees with a very similar microhabitat composition. In contrast, the results for foresters and students indicated (within their group) much more dissimilarity: the members of those groups lie much further apart on the plot than the forestry trainers.

The ANOSIM analysis indicated significant differences in dissimilarity between the expert groups $(P=0.001, R=0.33)$. The SIMPER analysis, in turn, revealed that differences between expert groups (pairwise group comparison) were attributed to only a few microhabitat types. The five most influential microhabitat types, explaining $46-64 \%$ of the observed dissimilarity, are shown in Figure 6 (more information on the codes used can be found in Figure 7). This plot illustrates that differences between groups were related to groups focusing on different types of microhabitats (e.g., CV24: Mold containing trunk cavity without ground contact. $\varnothing \geq 30 \mathrm{~cm}$-retained by all forestry trainers, a few students, but none of the foresters), on the one hand, and differing within-group disagreement with respect to microhabitat retention, on the on the hand (e.g., D13: dead branches and limbs/dead crown wood, $\varnothing 10-20 \mathrm{~cm}, \geq 50 \mathrm{~cm}$, not sun-exposed-had a low variance and medium value for forestry trainers but a high variance with both high and low values for foresters and students).

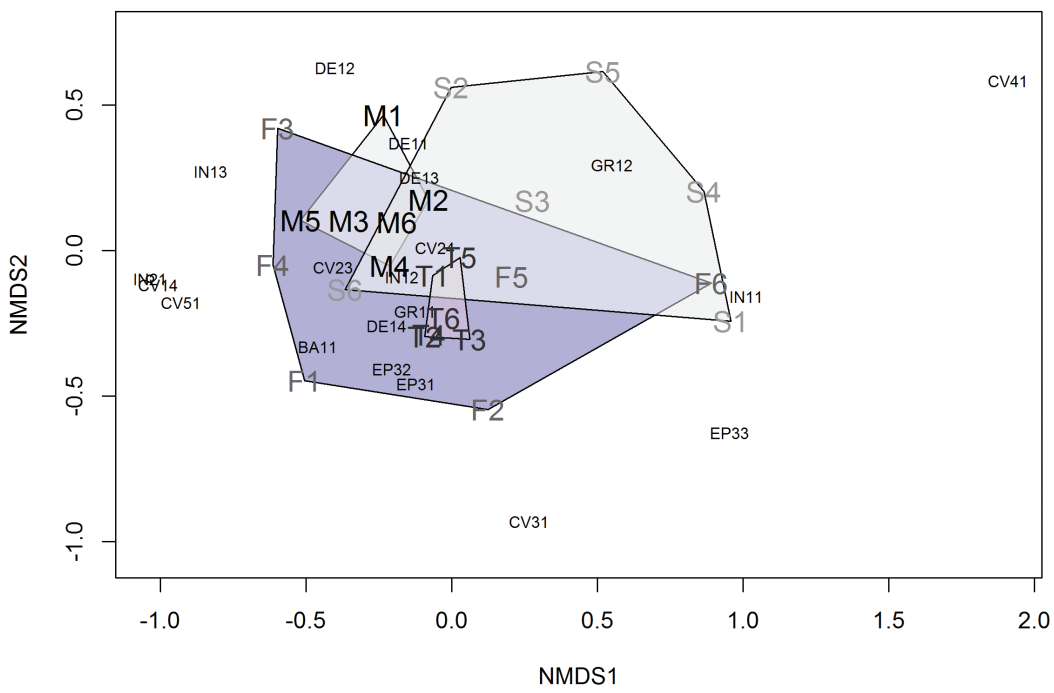

Figure 5. Nonmetric multidimensional scaling based on Bray-Curtis dissimilarity illustrating differences between expert groups as well as their relation to the different microhabitat types they retained through the selection of five habitat trees. Forestry trainers are clearly more clustered, and thus retained a more similar combination of microhabitats, than foresters and students. S: student; F: forester; T: forestry trainer; M: master solution; codes for the different microhabitats are explained in Figure 7. 


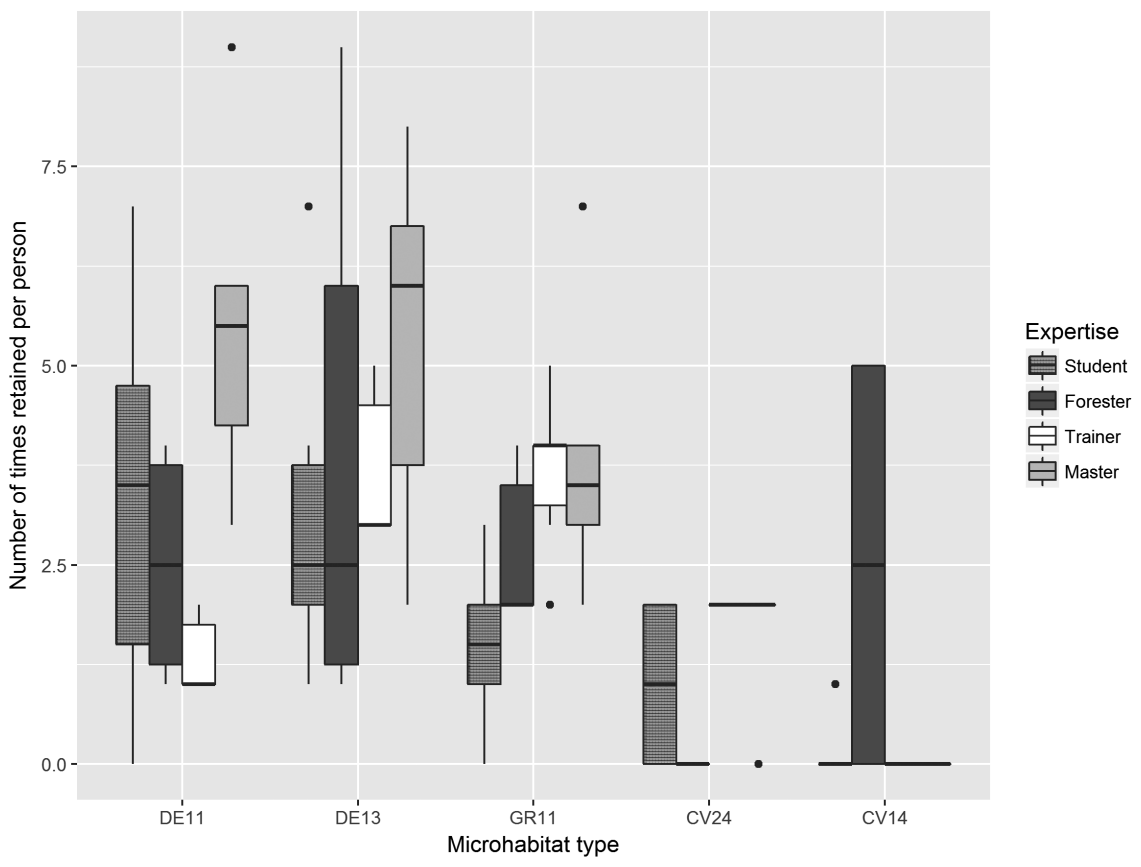

Figure 6. Boxplots for the five most important microhabitat types responsible for $46-64 \%$ of the dissimilarity between two different expert groups, as measured on the Bray-Curtis dissimilarity matrix. The $y$-axis indicates the total number of times a person retained a particular microhabitat type through the selection of five habitat trees on a 1-ha plot.

\section{Discussion}

\section{Lack of Agreement When Selecting Habitat Trees?}

When it comes to habitat-tree selection, the present study revealed that there is very low interpersonal agreement within and between groups. Most participants selected different trees as habitat trees. The few existing studies that focus on human treeselection behavior in forests also indicate that this low degree of agreement seems to be characteristic in this field. For example, a comparably low agreement level was observed in exercises where trees were to be selected for harvesting in the course of thinning operations in Ireland and Wales (Pommerening et al. 2015, Vítková et al. 2016). Although our results give the impression that persons have different ideas about which trees should be retained as habitat trees, this is not necessarily the case. In most, if not all, forests, there are plenty of options for the selection of (potential) habitat trees; in the case of habitat-trees selection, as well as for other tree-selection objectives, there can simply be several trees in the stand with very similar characteristics that are desired for the predefined goals, making them equally suitable for selection. This especially applies to stands where decisive structures are missing, e.g., extraordinary large and/or old trees. In stands where all trees look alike, and no trees stand out because of their particular habitat value, it will be harder to pinpoint the trees with the highest habitat values, and participants will select different trees as habitat trees. Rather than looking at the selection of individual trees, it makes more sense to compare the characteristics of the selected trees. In the case of habitat trees, characteristics such as the presence of microhabitats, microhabitat types, tree species, habitat, and economic value can be compared. In so doing, we found that participants seemed to be able to select habitat trees of comparable aggregated economic value, but quite diverging habitat value.

\section{Selecting Habitat Trees: Not as Easy as It Might Seem}

One of the instructions given to the participants was to select five trees with a high ecological/habitat value (on a 1-ha plot). Although there was no specific instruction with regard to the economic value of these trees, participants selected (intuitively) trees with a low economic value. Considering the ecology-economy tradeoff, the ideal habitat tree is sometimes characterized by a high ecological and low economic value (Niedermann-Meier et al. 2010) and the results are found to be in favor of the participants' decisions. However, this consistency regarding the economic value is in sharp contrast with the high variability of the selected trees' habitat values. Most participants included in their selection of five habitat trees both trees with a high habitat value and trees with a very low habitat value. Also, on stand level, the total retained habitat value was highly variable between the different participants (Figure 4). We distinguished at least six plausible explanations for this high variability in the selected trees' habitat values. The first explanation is an overlooking error (cf. Morrison 2016), which implies that participants are not able to detect all microhabitats. The study by Paillet et al. (2015) found "impressively low" detection levels for different microhabitats, with participants detecting on average only $10 \%$ of the cracks and bark pockets, $40 \%$ of the present woodpecker cavities, and $20 \%$ of the nonwoodpecker cavities. The second explanation is erroneous detection, with participants falsely detecting microhabitats. Erroneous detection is a problem that was observed by Paillet et al. (2015) in about $10 \%$ of the microhabitat detections (with a very high variability between microhabitats and an even higher variability between different persons). In contrast to most vegetation surveys, false detection might be linked not only to a misidentification, i.e., the microhabitat is not correctly identified (Morrison 2016), but also to the detection of a microhabitat where actually no microhabitat was present. The third explanation is incorrect attribute assignment, which implies that participants attribute a high habitat value to a certain 


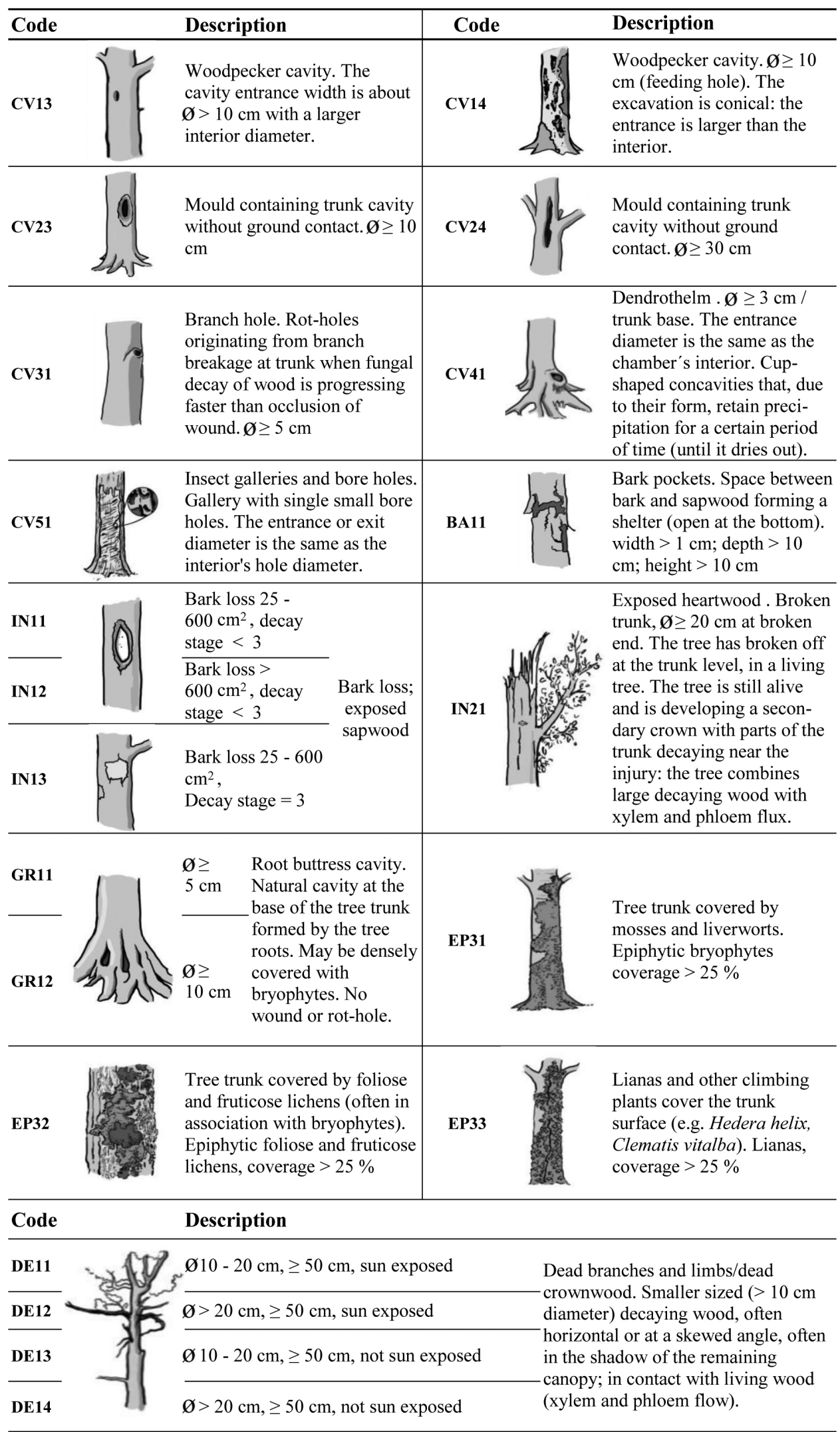

Figure 7. Microhabitat types, as categorized and described by Kraus et al. (2016), that have been retained by the participants during the marteloscope exercise. For more details on these, as well as other microhabitat types, consult Kraus et al. (2016).

microhabitat or tree that actually has a rather low habitat value, and vice versa. Divergent and/or insufficient level of knowledge on tree microhabitat structures is the most probable cause. In-depth knowledge of microhabitats' characteristics (rarity, time needed to develop, etc.) and their value for biodiversity could minimize this error. The fourth explanation is baseline data used for comparison, in 
which errors of the attributed habitat-tree characteristics could have occurred. Although these errors are assumed to be minimal, considering the thorough data-recording process (Schuck et al. 2015), the baseline values of the marteloscopes so far only take into account the present habitat and economic value of a tree, but do not account for a tree's future/potential habitat and economic value. It could be that participants did take this into account during tree selection. The fifth explanation is low occurrence of microhabitats. The Rosskopf Marteloscope is a typical example of an economically managed forest and indeed does not contain many microhabitats. The seemingly overall homogeneity of the stand makes habitat-tree selection a challenge. The sixth explanation is other considerations for decisionmaking. Participants could have taken into account other aspects besides habitat value to select habitat trees such as a tree's esthetic value, a tree's health condition, planned skid trails, etc. Further research is needed to account for these variables and explore deeper the reasoning process behind the observed decisions.

The above-mentioned figures on observers' (interpersonal) differences and misidentifications as mentioned by Paillet et al. (2015), a study in which participants only had to focus on microhabitat detection, are probably even higher in the present study because habitat-tree selection was only part of the assignment given, next to the thinning instructions. In addition, in the study presented here, participants had on average only $16 \mathrm{~s}$ to evaluate each tree [considering a 1-h time frame and a stand of 225 trees with $\mathrm{dbh}>30 \mathrm{~cm}$ - the threshold also applied in Paillet et al. (2015)], which is a much shorter time period than the $3 \mathrm{~min}$ (on average) they had in Paillet et al. (2015), although in the latter study, participants also had to classify the microhabitats. Hence, low detection rates of habitat trees (resp. microhabitats) in our study could partly be linked to the fact that it is practically not possible to study each of the 313 trees of the stand in detail. This lies also much closer to the real thinning situation, with often only about $15 \mathrm{~min}$ available per hectare for routine thinning. Thus, some microhabitats or trees could simply have been overlooked.

A detailed analysis of the selected microhabitats (NMDS, ANOSIM, and SIMPER) confirmed that forestry trainers were more consistent in their choices, focusing on similar microhabitats as compared with district foresters and students. The microhabitat types explaining the differences between groups were microhabitats located at the bottom, the roots of the tree, or high in the crown. These are places on the tree that are not in the normal line of sight and require additional effort and movement from the observer to notice them; moreover, these parts are not important when evaluating the economic value of a tree. It was also remarkable that certain microhabitat types were retained by certain expertise groups and not at all by the other participants; for example, half of the district foresters included a certain tree with woodpecker-feeding holes, whereas virtually none of the other participants retained this tree. The above results make clear that more professional training on microhabitats is needed to improve habitat-tree selection.

Comparing the results of the three participating groups, we found that professional expertise had an effect on habitat-tree selection, with forestry trainers outperforming the other two groups. Although not all variables indicated differences, the ones that did were always in favor of the forestry trainers. The significant effect of expertise contradicts the findings of Paillet et al. (2015), who found only marginal effects of expertise on microhabitat detection, although they were comparing students, foresters, and researchers in forest ecology, which represents similar differences in expertise to those in our study. Regarding the effect of experience, mixed results have been published from vegetation surveys with some studies finding significant differences (e.g., McCune et al. 1997, Scott and Hallam 2003, Bergstedt et al. 2009, Morrison 2016) whereas others do not (e.g., Cheal 2008, Ahrends et al. 2011, Moore et al. 2011, Burg et al. 2015).

Finally, our results clearly indicated that the selection of habitat trees can still be improved, as we found high intrapersonal variability and significant differences with respect to several habitat-related features between participant groups and the mastersolution (Figure 4). In addition, it is remarkable that participants showed clearly more agreement and consistency regarding the habitat trees' economic value. Without sufficient training and experience, the economic value of a tree is certainly not straightforward to assess but presumably the participants were more familiar with the concept. Hence, it can be assumed that more knowledge and familiarity with microhabitats and tree's ecological values would lead to more agreement and consistency when habitat trees are to be selected. A certain degree of variability seems nevertheless to be inherent when it comes to identifying microhabitats and habitat trees (Paillet et al. 2015), especially because of the reduced visibility from the ground at higher heights and in the crown. This variability is also found apparent in many other fields of biological study (Elphick 2008). We have shown conclusively that selecting the trees with the highest habitat values from a stand is not straightforward and is characterized by large interpersonal differences. However, that habitat-tree selection can be learned is illustrated by the better and more consistent results of participants' with more expertise.

Our study only took into account the present economic and habitat value of each tree and discarded the future values. Future economic and habitat-tree values are difficult to assess because the knowledge and information required are often not available (i.e., tree growth, wood-price fluctuations) or they are concerned with topics that have scarcely been investigated (i.e., development of tree microhabitats over time). The impact of not including future values in our assessment is largely dependent on the degree to which participants actually tried to take into account such future values, especially those of the future habitat value, when selecting habitat trees. Because overall very little is known on how habitat values develop over time, we assume that participants also possess little knowledge on this topic and we thus assume that participants took this into account to a very limited degree only. One way to grasp this would be to investigate the participant's rationales for tree selection in more detail. These could possibly also reveal further aspects influencing decisionmaking that were currently not accounted for (e.g., location of skid trails, risks on felling damage, slope steepness, etc.).

Our study had a small sample size with only six individuals and 30 tree observations per expertise group. The high variability of the data for most observed variables, as well as several almost significant statistical test results, indicates that future experiments would benefit from a larger sample size.

\section{Conclusions for Habitat-Tree Selection in Practice}

Habitat-tree selection is subject to a strong "observer effect" when it comes to the habitat value and related variables of the retained trees. This variability should be taken into account when dealing with the selection of habitat trees. Currently, habitat-tree selection 
is seen as a task that can be performed by nonexperts (Regnery et al. 2013) and for which citizens have already been mobilized, e.g., in Australia (City of Melbourne 2017) and Denmark (Naturstyrelsen 2017). Indeed, the observation and identification of tree microhabitats are probably more straightforward than that of many other attributes related to forest biodiversity such as birds, beetles, fungi, etc., which depend on experts for species determination. Therefore, the identification of certain structures on the tree, i.e., microhabitats, which are related to biodiversity, is a promising approach, because it enables nonspecialists to make informed decisions. However, our study and those of other scholars (e.g., Paillet et al. 2015) have demonstrated the many challenges in collecting representative and repeatable data regarding microhabitats. In addition, stand homogeneity and the lack of clear microhabitat structures, which is the case in many forests (including our study area), complicate microhabitat identification and habitat-tree selection. Hence, the mobilization of nonexperts for habitat-tree selection should be well considered and is probably only effective if simple microhabitat typologies are applied, thus reducing the observer effect. Nonetheless, combining a very simple typology and activating nonexperts, including citizens, might be an interesting cost-effective approach to collect much more-but coarser — microhabitat-related data.

The present study shows that expertise has an impact on habitattree selection. Moreover, the fact that, in our study, forestry trainers outperformed the foresters and that there were no significant differences between foresters and students could result from the difficulty in building up knowledge on microhabitats merely through professional experience as a forester. In addition, the concepts of tree microhabitats and habitat-tree retention have rather recently been developed, and foresters have probably not come into contact with them during their formation. Hence, this expertise should be acquired somehow, and we recommend that persons involved in habitat-tree selection receive proper training and instructions (Chen et al. 2009, Paillet et al. 2015, Morrison 2016). On the one hand, it is crucial they have sufficient knowledge on different microhabitat structures, their characteristics, and their value for different species and species groups. On the other hand, practical training sessions on microhabitat recognition and classification will be needed that ultimately have to be adapted to realworld working conditions, i.e., combining habitat-tree selection with tree selection for thinning within a restricted time frame.

In addition to proper training, to improve habitat-tree selection, we also suggest the development of clear practical guidelines that enable practitioners to easily assess a tree's habitat value. These guidelines should find their roots in a thorough, science-based classification of the different tree microhabitats and their value for biodiversity (Larrieu et al. 2018). However, because, in practice, the time to assess each individual tree is limited and to minimize observer effects, we suggest a simplified microhabitat-assessment protocol. The microhabitat assessment should apply a simpler microhabitat typology (Larrieu et al. 2018) and emphasize the recognition of key microhabitats (Großmann et al. 2018) with a high (umbrella) value for biodiversity or certain target species (taking into account that key microhabitats can be distinguished) and should focus on those features that have a high potential to develop into key microhabitats over time. With current research going in this direction (Vuidot et al. 2011, Winter et al. 2015, Larrieu et al. 2017, Großmann et al. 2018, Larrieu et al. 2018), hopefully it is just a matter of time before such practical guidelines are provided.
Nevertheless, it should be kept in mind that if habitat trees and tree microhabitats are to be used as proxies to assess forest biodiversity, which has been proposed by several authors (Winter and Moller 2008, Michel and Winter 2009, Regnery et al. 2013), there is still a lot to be investigated on their reliability as biodiversity indicators.

\section{Literature Cited}

Ahrends, A., C. Rahbek, M.T. Bulling, et al. 2011. Conservation and the botanist effect. Biol. Conserv. 144(1):131-140. doi:10.1016/j. biocon.2010.08.008.

Allenspach, K., P. Junod, and R. Lüscher. 2015. Erfahrungsbericht aus dem Voralpen-Marteloskop. Wald und Holz 11(15):35-38.

Beasley, T.M., and R.E. Schumacker. 1995. Multiple regression approach to analyzing contingency tables: Post hoc and planned comparison procedures. J. Exp. Educ. 64(1):79-93. doi:10.1080/0022097 3.1995.9943797.

Bergstedt, J., L. Westerberg, And P. Milberg. 2009. In the eye of the beholder: Bias and stochastic variation in cover estimates. Plant Ecol. 204(2):271-283. doi:10.1007/s11258-009-9590-7.

Burg, S., C. Rixen, V. Stockli, and S. Wipf. 2015. Observation bias and its causes in botanical surveys on high-alpine summits. J. Veg. Sci. 26(1):191-200. doi:10.1111/jvs.12211.

Bütler, R., ANd T. LAchat. 2009. Wälder ohne Bewirtschaftung: Eine Chance für die saproxylische Biodiversität. Schweiz. Z. Forstwes. 160(11):324-333. doi:10.3188/szf.2009.0324.

Bütler, R., T. Lachat, L. Larrieu, and Y. Paillet. 2013. Habitat trees: Key elements for forest biodiversity. P. 84-91, in Integrative approaches as an opportunity for the conservation of forest biodiversity, Kraus, D., and F. Krumm (eds.). European Forest Institute, Freiburg.

Cheal, D. 2008. Repeatability of covers estimates? Ecol. Manag. Restor. 9:67-68. doi:10.1111/j.1442-8903.2008.00390.x.

Chen, G.K., M. Kery, J.L. Zhang, and K.P. Ma. 2009. Factors affecting detection probability in plant distribution studies. J. Ecol. 97(6):13831389. doi:10.1111/j.1365-2745.2009.01560.x.

City of melbourne. 2017. Habitat tree inventory. Available at: https:// participate.melbourne.vic.gov.au/citizenforester/habitat-tree-inventory; last accessed July 17, 2017.

Clarke, K.R., AND R.M. Warwick. 2001. Changes in marine communities: An approach to statistical analysis and interpretation. PRIMER-E, Plymouth.

Ehrgott, M. 2005. Multicriteria optimization. Springer, Heidelberg.

ELPHICK, C.S. 2008. How you count counts: the importance of methods research in applied ecology. J. Appl. Ecol. 45(5):1313-1320. doi:10.1111/j.1365-2664.2008.01545.x.

Großmann, J., J. Schultze, J. Bauhus, and P. Pyttel. 2018. Predictors of microhabitat frequency and diversity in mixed mountain forests in South-Western Germany. Forests 9(3):104. doi:10.3390/f9030104.

Gustafsson, L., S.C. Baker, J. Bauhus, et Al. 2012. Retention forestry to maintain multifunctional forests: A world perspective. Bioscience 62(7):633-645. doi:10.1525/bio.2012.62.7.6.

Horak, J., E. Chumanova, and J. Hilszczanski. 2012. Saproxylic beetle thrives on the openness in management: A case study on the ecological requirements of Cucujus cinnaberinus from Central Europe. Insect Conserv. Diver. 5(6):403-413. doi:10.1111/j.1752-4598.2011.00173.x.

IBM CoRp. 2015. IBM SPSS statistics for Windows. IBM Corp, Armonk, NY.

Kiehne, J. 2015. Das Marteloskop Rosskopf als Grundlage zur Beurteilung von betriebswirtschaftlichen und naturschutzfachlichen Aspekten im Bergmischwald. M.Sc. thesis, Albert-Ludwigs-Universität Freiburg im Breisgau, Freiburg. 136 p.

Kraus, D., R. Bütler, F. Krumm, et Al. 2016. Catalogue of tree microhabitats—Reference field list. European Forest Institute. Integrate+ Technical Paper. 16 p. 
Kraus, D., AND A. Schuck. 2016. Mikrohabitatstrukturen im Wald: Ein Schlüssel zur Erhaltung von gefährdeten Arten. ANLiegen Natur 38(1):99-101.

Kraus, D., A. Schuck, F. Krumm, et al. 2018. Seeing is building better understanding - the Integrate+ Marteloscopes. European Forest Institute. Integrate+ Technical paper $26.3 \mathrm{p}$.

Kraus, D., A. Schuck, A. Schmitt, and P. Pyttel. 2015. The Rosskopf Marteloscope field guide. European Forest Institute. Integrate+Technical Paper No 3. 12 p.

Kruskal, J., And M. Wish. 1987. Multidimensional scaling. Sage Publications, Beverly Hills, CA.

Larrieu, L., A. Cabanettes, A. Brin, C. Bouget, and M. Deconchat. 2014. Tree microhabitats at the stand scale in montane beech-fir forests: Practical information for taxa conservation in forestry. Eur. J. Forest Res. 133(2):355-367. doi:10.1007/s10342-013-0767-1.

Larrieu, L., A. Cabanettes, N. Gouix, L. Burnel, C. Bouget, and M. Deconchat. 2017. Development over time of the tree-related microhabitat profile: The case of lowland beech-oak coppice-withstandards set aside stands in France. Eur. J. Forest Res. 136(1):37-49. doi:10.1007/s10342-016-1006-3.

Larrieu, L., Y. Paillet, S. Winter, et al. 2018. Tree related microhabitats in temperate and Mediterranean European forests: A hierarchical typology for inventory standardization. Ecol. Indic. 84:194-207. doi:10.1016/j.ecolind.2017.08.051.

Lehikoinen, A., P. Lehikoinen, A. Linden, and T. Laine. 2011. Population trend and status of the endangered white-backed woodpecker Dendrocopos leucotos in Finland. Ornis Fennica 88(4):195-207.

McCune, B., J.P. Dey, J.E. Peck, et Al. 1997. Repeatability of community data: Species richness versus gradient scores in large-scale lichen studies. Bryologist 100(1):40-46. doi:10.2307/3244385.

Mergner, U., and D. Kraus. 2013. Box 46. Protection despite utilization-the biodiversity concept of the Ebrach State Forest Enterprise in the Steigerwald region of Franconia (Bavaria, Germany). P. 259-261 in Integrative approaches as an opportunity for the conservation of forest biodiversity, Kraus, D., and F. Krumm (eds.). European Forest Institute, Freiburg.

Meyer, P., And M. Schmidt. 2008. Aspekte der Biodiversität von Buchenwäldern-Konsequenzen für eine naturnahe Bewirtschaftung Beiträge aus der NW-FVA. Band 3:159-192.

Michel, A.K., And S. Winter. 2009. Tree microhabitat structures as indicators of biodiversity in Douglas-fir forests of different stand ages and management histories in the Pacific Northwest, USA. Forest Ecol. Manag. 257(6):1453-1464. doi:10.1016/j.foreco.2008.11.027.

Moore, J.L., C.E. Hauser, J.L. Bear, N.S.G. Williams, and M.A. McCarthy. 2011. Estimating detection-effort curves for plants using search experiments. Ecol. Appl. 21(2):601-607. doi:10.1890/10-0590.1.

Mordini, M., and P. Rotach. 2010. Die Eichenbestände fördern. Wald und Holz 7(10):39-41.

Morrison, L.W. 2016. Observer error in vegetation surveys: A review. J. Plant Ecol. 9(4):367-379. doi:10.1093/jpe/rtv077.

Naturstyrelsen. 2017. Livstreer. Available at: http://naturstyrelsen.dk/ naturbeskyttelse/naturprojekter/livstraeer/; last accessed July 17, 2017.

Niedermann-Meier, S., M. Mordini, R. Bütler, and P. Rotach. 2010. Habitatbäume im Wirtschaftswald: Ökologisches Potential und finanzielle Folgen für den Betrieb. Schweiz. Z. Forstwes. 161:391-400. doi:10.3188/szf.2010.0391.

Paillet, Y., P. Coutadeur, A. Vuidot, F. Archaux, and F. Gosselin. 2015. Strong observer effect on tree microhabitats inventories: A case study in a French lowland forest. Ecol. Indic. 49:14-23. doi:10.1016/j. ecolind.2014.08.023.

Palmer, M.W. 1986. Pattern in corticolous bryophyte communities of the North-Carolina Piedmont-do mosses see the forest or the trees. Bryologist 89(1):59-65. doi:10.2307/3243078.
Petit, S., C. Sanchez, and M. Bruciamacchie. 2014. Les marteloscopes: Des outils de dialogue pour la gestion forestière. Forêt Wallonne 132:40-49.

Pommerening, A., C. Pallarés Ramos, W. Kedziora, J. Haufe, and D. Stoyan. 2018. Rating experiments in forestry: How much agreement is there in tree marking? PLoS One 13(3):e0194747. doi:10.1371/ journal.pone.0194747.

Pommerening, A., L. Vítková, X. Zhao, and C. Pallarés Ramos. 2015. Toward understanding human tree selection behaviour, in Forest Facts $N^{\circ} 9$. SLU, Uppsala.

Quinto, J., E. Mico, A.P. Martinez-Falcon, E. Galante, and M.D. Marcos-Garcia. 2014. Influence of tree hollow characteristics on the diversity of saproxylic insect guilds in Iberian Mediterranean woodlands. J. Insect Conserv. 18(5):981-992. doi:10.1007/ s10841-014-9705-x.

R Core TEAm. 2017. R: A language and environment for statistical computing. R Foundation for Statistical Computing, Vienna, Austria.

Ranius, T., ANd J. Hedin. 2001. The dispersal rate of a beetle, Osmoderma eremita, living in tree hollows. Oecologia 126(3):363-370. doi:10.1007/ s004420000529.

Regnery, B., D. Couvet, L. Kubarek, J.F. Julien, and C. Kerbiriou. 2013. Tree microhabitats as indicators of bird and bat communities in Mediterranean forests. Ecol. Indic. 34:221-230. doi:10.1016/j. ecolind.2013.05.003.

Schuck, A., F. Krumm, and D. Kraus. 2015. Integrate+ Marteloscopes: Description of parameters and assessment procedures. European Forest Institute. Integrate+ Technical Paper No. 18. 16 p.

Scott, W.A., and C.J. Hallam. 2003. Assessing species misidentification rates through quality assurance of vegetation monitoring. Plant Ecol. 165(1):101-115. doi:10.1023/A:1021441331839.

Simonsson, P., L. Gustafsson, ANd L. OstLund. 2015. Retention forestry in Sweden: Driving forces, debate and implementation 1968-2003. Scand. J. Forest Res. 30(2):154-173. doi:10.1080/02827581.2014.968201.

Spinelli, R., N. Magagnotti, L. Pali, and M. Soucy. 2016. Comparing tree selection as performed by different professional figures. For. Sci. 62(2):213-219. doi:10.5849/forsci.15-062.

Sydor, T., R.A. Kluender, R.L. Busby, and M. Pelkki. 2004. Productivity and cost of marking activities for single-tree selection and thinning treatments in Arkansas. Forest Prod. J. 54(3):59-65.

Van Daele, S., G. Geudens, W. Sauwens, and B. Van der Aa. 2011. Marteloscoop: Van rozen en Chinese snorren. Bosrevue 36:5-7.

Vandekerkhove, K., A. Thomaes, and B. Jonsson. 2013. Connectivity and fragmentation: Island biogeography and metapopulation applied to old-growth-elements. P. 104-115 in Integrative approaches as an opportunity for the conservation of forest biodiversity, Kraus, D., and F. Krumm (eds.). European Forest Institute, Freiburg.

Vítrová, L., A.N. Dhubhain, and A. Pommerening. 2016. Agreement in tree marking: What is the uncertainty of human tree selection in selective forest management? For. Sci. 62(3):288-296. doi:10.5849/ forsci.15-133.

Vuidot, A., Y. Paillet, F. Archaux, and F. Gosselin. 2011. Influence of tree characteristics and forest management on tree microhabitats. Biol. Conserv. 144(1):441-450. doi:10.1016/j.biocon.2010.09.030.

Winter, S., J. Hofler, A.K. Michel, A. Bock, and D.P. Ankerst. 2015. Association of tree and plot characteristics with microhabitat formation in European beech and Douglas-fir forests. Eur. J. Forest Res. 134(2):335-347. doi:10.1007/s10342-014-0855-x.

Winter, S., ANd G.C. Moller. 2008. Microhabitats in lowland beech forests as monitoring tool for nature conservation. Forest. Ecol. Manag. 255(3-4):1251-1261. doi:10.1016/j.foreco.2007.10.029.

Zielinski, W.J., ANd F.V. Schlexer. 2015. Changes in the structural and functional characteristics of fisher (Pekania pennanti) rest structures over time. Northwest Sci. 89(2):148-153. doi:10.3955/046.089.0206.

ZuCCHINI, W., AND K. vON GADOW. 1995. Two indices of agreement among foresters selecting trees for thinning. For. Landsc. Res. 1:199-206. 